\title{
Size Specification for Customized Production Size and 3D Avatar : An Apparel Industry Case Study
}

\author{
Young Lim Choi ${ }^{\dagger}$ \\ Dept. of Fashion Design/Art \& Design Institute, Daegu University; Daegu, Korea
}

\begin{abstract}
Fashion industry has tried to adopt the virtual garment technology to reduce the time and effort spent on sample creation. For garment manufacturers to adopt the virtual garment technology as an alternative to sample creation, 3D avatars that meet the needs of each brand should be developed. Virtual garment softwares that are available in the market provide avatars with standardized body models and allow to modify the size by manually entering size specifications. This study proposed a methodology to develop size specifications for 3D avatars as well as brand-customized production sizes. For this, a man's fashion brand which is using virtual garment technology is selected. And the Size Korea database is used to develop size specification based on the customers' body shape. This study developed regression equations on body size specifications, which in turn proposed a regression model to proportionately change size specifications of 3D fitting-models. Based on the each body size calculated by the regression model, a standard model is created, and the skeleton-skin algorithm is applied to the regression model to obtain the results of size changes. Then, the 3D model sizes are tested for size changes as well as measured, which verifies that the regression model reflects body size changes.
\end{abstract}

Key words : size specification, 3D-fitting model, 3D avatar, virtual garment, body measurement

\section{Introduction}

$3 \mathrm{D}$ virtual garment technology is emerging as a new paradigm of the fashion industry, backed by rapidly evolving computer graphics technology and the apparel CAD program. This 3D technology began to be used as a sales and marketing tool in the virtual world like Second Life. Browzwear developed and commercialized Vstitcher, which enables putting garments on virtual body models for 3D designs(Gerber Technology, 2008). 3D runway designer Optitex allows production and image files in $2 \mathrm{D}$ and $3 \mathrm{D}$ to be sent between designers and production professionals so that they can easily modify these images on screen together in real time(Optitex, 2008). CLO Virtual Fashion INC. developed CLO 3D, which puts 2D apparel patterns on virtual models, and has distributed the software to global fashion manufacturers(CLO Virtual Fashion INC, 2014). As small quantity batch production, global manufacturing and distribution, and fast fashion have become the norm of the fashion industry, virtual garments are replacing physical sample, helping the industry save the time and costs spent on samples.

For garment manufacturers to adopt the virtual garment technology as an alternative to sample creation, 3D avatars that meet the needs of each brand should be developed(Yang \& Choi, 2013). Virtual garment softwares that are available in the market provide avatars with standardized body models and allow to modify the

†Corresponding author; Young Lim Choi

Tel. +82-53-850-6827, Fax. +82-53-850-6829

E-mail: orangebk@daegu.ac.kr size by manually entering size specifications. Studies on 3D avatar modeling for virtual garment simulation(Charlie, 2005; Kim \& Park, 2004; Seo \& Magnenat-Thalmann, 2004; Allen et al., 2003; Li \& Chen, 2009; Baek \& Lee, 2012) have been published, but their focus has remained on modeling methods and modification of a standard human body template.

The existing system of apparel size was based on the plan of mass production with little variety, requiring a simplified sizing system. However, as consumers have a need to express their originality and the distribution flows change, the preferred method to produce garments leans more towards the idea of small quantity batch production and mass customization(Choi, 2012). However, the existing researches to set the size of men's wear were created for single garment item(Seong \& Park, 2012; Yoon \& Suh, 2011). Therefore, a size specification system to create $3 \mathrm{D}$ avatar that reflect different body shapes is required.

Each garment manufacturer designs products aiming at its target market, and has production sizes and grading rules that reflect target consumers' body shape. Accordingly, to leverage the virtual garment technology, garment manufacturers need to secure production sizes fitting their target market. Also, size specifications should be provided to modify $3 \mathrm{D}$ avatars to fit into the production sizes. However, little research has been conducted on body size analysis that can be used to develop production sizes customized to the target markets of garment manufacturers or body modeling for each size cell.

Thus, this study will select a man's fashion brand and analyze 
body shapes of the target customers in order to improve the production size system and to propose body size specifications accordingly. Ultimately, this study will propose a methodology to develop size specifications for 3D avatars as well as brand-customized production sizes.

\section{Materials and methods}

\subsection{Research subjects}

This researcher first selected a man's fashion brand(Brand A) which is using virtual garment technology in selling/producing their clothes and analyzed ages of the customers who purchased the brand items in 2011. Then, those aged 32 to 65 , accounting for more than $1 \%$ of the total customers, were chosen as the research subjects. To determine size cells and size specifications of each cell, 3D body measurements of 1,034 men aged 32 to 65 , among the 5th Size Korea dataset, were analyzed(Korean Agency for Technology and Standards, 2004).

\subsection{Data analysis}

As per the man's wear size standards of the Korean Industrial Standards (KS), statures were sectioned by every $5 \mathrm{~cm}$ and chest circumferences by every $3 \mathrm{~cm}$; and crosstabulation analysis on two variables were conducted. Sections where $1.5 \%$ or more subjects belonged to were identified as high frequency ranges; and the results were compared with the standard size system. Finally, the research proposed a plan to improve the garment production size

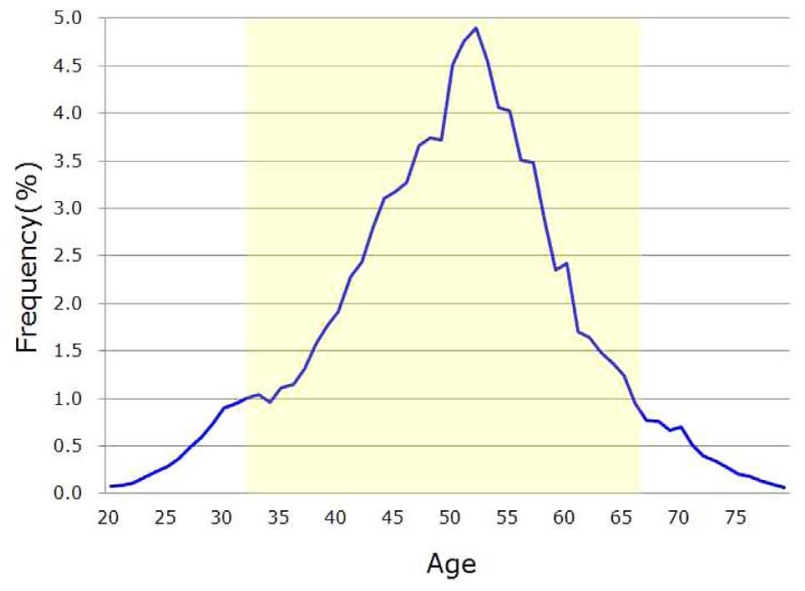

Fig. 1. Customer frequency $(\%)$ for age.

system.

Regarding body sizes, factor analysis was conducted to identity representative factors. Among the 3D measurements of men aged $32-65$ in the 5th Size Korea dataset, a total of 34 items(13 height items, 16 circumference items, and 5 length items) were analyzed(Table 1). Factors were extracted by principal component analysis(PCA), and determined among those with an eigenvalue of 1.00 or over in accordance with a scree diagram; and the component matrix was vertically rotated by Varimax.

Last, regression analysis was conducted to develop size specifications for each section. For the regression analysis, waist circumferences and statures were entered as independent variables,

Table 1. Body measurement

\begin{tabular}{|c|c|c|c|c|c|}
\hline \multicolumn{2}{|r|}{ Height } & \multicolumn{2}{|r|}{ Circumference } & \multicolumn{2}{|r|}{ Length } \\
\hline 1 & Stature & 1 & Neck circ. & 1 & Posterior shoulder length \\
\hline 2 & Cervical height & 2 & Chest circ. & 2 & Interscye, front \\
\hline 3 & Axilla height & 3 & Waist circ. & 3 & Interscye, back \\
\hline 4 & Bust height & 4 & Waist circ.(omphalion) & 4 & Upperarm length \\
\hline 5 & Waist height & 5 & Abdominal circ. & 5 & Arm length \\
\hline 6 & Omphalion height & 6 & Hip circ. & & \\
\hline 7 & Abdominal height & 7 & Thigh circ. & & \\
\hline 8 & Hip height & 8 & Midthigh circ. & & \\
\hline 9 & Gluteal fold height & 9 & Knee circ. & & \\
\hline 10 & Thigh height & 10 & Calf circ. & & \\
\hline 11 & Crotch height & 11 & Minimum leg circ. & & \\
\hline 12 & Knee height & 12 & Foot circ. & & \\
\hline \multirow[t]{4}{*}{13} & Calf height & 13 & Upper arm circ. & & \\
\hline & & 14 & Elbow circ. & & \\
\hline & & 15 & Forearm circ. & & \\
\hline & & 16 & Wrist circ. & & \\
\hline
\end{tabular}


and the reference sizes as dependent variables This regression analysis considered all the data captured in the high frequency ranges because each size cell has only a limited number of samples, which may produce distorted results if the average is used for calculation.

For statistical analysis, SPSS 18.0 was utilized.

\section{Results}

\subsection{Current size standard}

This researcher analyzed the jacket size system of Brand A, and found that the size cell was quoted by every $3 \mathrm{~cm}$ of chest circumference, $3 \mathrm{~cm}$ of waist circumference and $5 \mathrm{~cm}$ of stature(Table 2). Brand A produces jackets in 11 different sizes, but the drop from chest to waist circumferences remains at a constant $15 \mathrm{~cm}$. This shows the size standard was developed on the basis of chest circumference and stature, not considering the drop.

Among the 5th Size Korea dataset, statures and chest circumferences of 1,034 men aged 32 65 were extracted and respectively sectioned by every $5 \mathrm{~cm}$ and $3 \mathrm{~cm}$; and crosstabulation analysis on two variables was conducted(Table 3). The shadow areas on the Table 3 are high frequency ranges with the frequency of $1.5 \%$ or above. Bold cells on the table are 13 size categories of Brand A, covering $50 \%$ of the total. As the table suggests, production sizes of Brand A were different from actual size distribution of the customers. In particular, two sizes of the stature $180 \mathrm{~cm}$ section were included although their frequencies were as low as $0.77 \%$ and

Table 2. Size system of classic jacket(chest-waist-stature)

\begin{tabular}{|c|c|c|c|c|}
\hline Chest Circ. & 165 & 170 & 175 & 180 \\
\hline 94 & $94-79-165$ & & & \\
\hline 97 & $97-82-165$ & $97-82-170$ & & \\
\hline 100 & $100-85-165$ & $100-85-170$ & $100-85-175$ & $100-85-180$ \\
\hline 103 & & $103-88-170$ & $103-88-175$ & \\
\hline 106 & & $106-91-170$ & 106-91-175 & $106-91-180$ \\
\hline 109 & & & & \\
\hline 112 & & & $112-97-175$ & \\
\hline
\end{tabular}

Table 3. Result of crosstabulation for aged 32-65

\begin{tabular}{|c|c|c|c|c|c|c|c|c|c|}
\hline $\begin{array}{ll} & \text { Stature } \\
\text { Chest } & \end{array}$ & 150 & 155 & 160 & 165 & 170 & 175 & 180 & 185 & Tot. \\
\hline 79 & & 0.10 & & & & & & & 0.10 \\
\hline 85 & & 0.10 & 0.10 & 0.29 & 0.10 & 0.10 & & & 0.68 \\
\hline 88 & 0.19 & 0.19 & 0.58 & 0.77 & 0.00 & 0.19 & 0.10 & & 2.03 \\
\hline 91 & & 0.39 & 0.97 & 1.55 & 1.35 & 0.68 & & & 4.93 \\
\hline 94 & 0.19 & 0.39 & 1.84 & 2.22 & 2.80 & 0.77 & 0.29 & & 8.51 \\
\hline 97 & & 0.68 & 2.32 & 5.32 & 5.42 & 3.29 & 0.48 & & 17.50 \\
\hline 100 & & 0.58 & 3.00 & 5.61 & 7.35 & 2.71 & 0.77 & 0.10 & 20.12 \\
\hline 103 & 0.19 & & 1.84 & 6.00 & 5.32 & 3.00 & 0.77 & 0.19 & 17.31 \\
\hline 106 & & 0.19 & 1.35 & 4.26 & 4.26 & 2.90 & 1.06 & 0.10 & 14.12 \\
\hline 109 & 0.10 & & 0.19 & 1.93 & 2.03 & 1.74 & 0.87 & & 6.87 \\
\hline 112 & & 0.10 & 0.10 & 0.58 & 1.64 & 0.77 & 0.77 & 0.19 & 4.16 \\
\hline 115 & & & & 0.58 & 0.97 & 0.48 & 0.39 & & 2.42 \\
\hline 118 & & & & 0.10 & 0.29 & 0.10 & 0.19 & & 0.68 \\
\hline 121 & & & 0.10 & & 0.10 & & 0.10 & & 0.29 \\
\hline 124 & & & & 0.10 & & 0.10 & & & 0.19 \\
\hline 127 & & & & & 0.10 & & & & 0.10 \\
\hline Tot. & 0.68 & 2.71 & 14.02 & 31.04 & 30.46 & 15.18 & 5.80 & 0.58 & 100 \\
\hline
\end{tabular}


$1.06 \%$.

\subsection{Improvement of Production Size}

To narrow the gap between production size and actual size distribution, the stature sections were adjusted and crosstabulation analyzed. In addition, statures were also divided into $167 \mathrm{~cm}, 172$ $\mathrm{cm}$ and $177 \mathrm{~cm}$ groups (while maintaining the section size of $5 \mathrm{~cm}$ ) and crosstabulation analysis was conducted. The results are presented in the Table 4. For the chest size of 103, 106 and 112, the adjusted stature groups of 167, 172, and 177 delivered higher densities to high frequency ranges. Based on the results, 16 sizes were identified, covering $61.90 \%$ of the total(Table 5). Although it is better than the previous $50 \%$, the number of production sizes also increased to 16 from 13. Thus, cover efficiency(coverage/number of sizes) meagerly improved from 3.85 to 3.87 . What should be noted, however, is that the chest size of 109 came into the size system, which was excluded from the existing production size. Thus, the new size system is expected to improve consumers' rights to size selection and satisfaction as well as garment fitting.

\subsection{Selection of key variables}

Key variables that affect body shapes were identified and factor analysis was conducted thereon. To set up the variables that determine adult-male body shapes, 1,034 men aged 32 65 were analyzed. As shown Table 6, three factors were found by the factor analysis, and their eigenvalues after Varimax rotation were 1.00 or

Table 4. Result of crosstabulation of adjusted stature

(unit; \%)

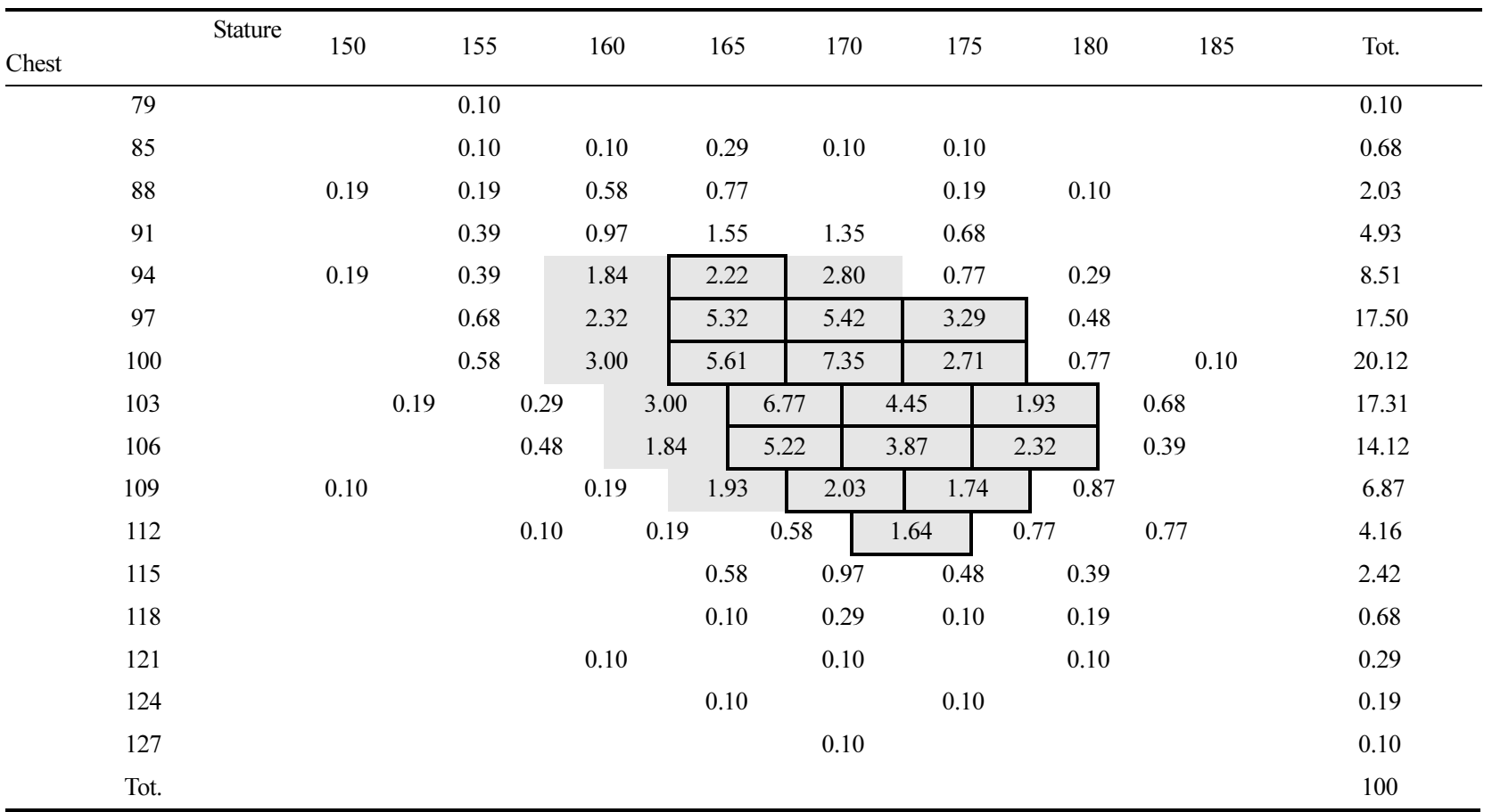

High frequency ranges of Size Korea dataset

Purposed size for Brand A

Table 5. Proposed size system of classic jacket

\begin{tabular}{|c|c|c|c|c|c|c|c|}
\hline Chest Circ. & \multicolumn{2}{|l|}{165} & \multicolumn{2}{|l|}{170} & 175 & & 180 \\
\hline 94 & \multicolumn{2}{|l|}{$94-79-165$} & & & & & \\
\hline 97 & \multicolumn{2}{|l|}{$97-82-165$} & \multicolumn{2}{|l|}{$97-82-170$} & \multicolumn{2}{|l|}{$97-82-175$} & \\
\hline 100 & \multicolumn{2}{|l|}{$100-85-165$} & $100-85-170$ & & $100-85-175$ & & \\
\hline 103 & & $103-88-167$ & & $103-88-172$ & & 103-88-177 & \\
\hline 106 & & $106-91-167$ & & $106-91-172$ & & 106-91-177 & \\
\hline 109 & & & $109-94-170$ & & 109-94-175 & & \\
\hline 112 & & & & $112-97-172$ & & & \\
\hline
\end{tabular}


over, with the variance explained of $75.12 \%$. Factor 1 includes mostly heights, such as axilla height, cervical height, bust height, stature, gluteal fold height and crotch heigh, hence named 'height factors'. Factor 2 include circumferences, such as bust circumference, thigh circumference, waist circumference and hip circumference, hence named 'obesity factors'. Factor 3 includes posterior shoulder length, interscye-front, interscye-back, upperarm length and arm length, hence named 'shoulder factors'.

\subsection{Development of regression model}

As the table suggests, high frequency ranges are widely differed in the number of the frequency from 17 to 76 that is not standardized yet. To develop size specifications of each size cell, regression equations were developed by including all the data belonging to each size cell.

Regression analysis was conducted by having statures and chest circumferences, which are the most representative variables of

Table 6. Rotated component matrix of body measurements

\begin{tabular}{|c|c|c|c|c|c|c|}
\hline & \multirow{2}{*}{ Factor } & \multicolumn{3}{|c|}{ Item Loadings } & \multirow{2}{*}{ Eigenvalue } & \multirow{2}{*}{$\begin{array}{c}\text { Variance Explained } \\
(75.12 \%)\end{array}$} \\
\hline & & 1 & 2 & 3 & & \\
\hline \multirow{13}{*}{ Height } & Omphalion height & .977 & .003 & .086 & \multirow{13}{*}{12.64} & \multirow{13}{*}{37.18} \\
\hline & Axilla height & .973 & .043 & .071 & & \\
\hline & Cervical height & .970 & .100 & .078 & & \\
\hline & Bust height & .969 & .071 & .070 & & \\
\hline & Gluteal fold height & .968 & .057 & .132 & & \\
\hline & Stature & .967 & .081 & .043 & & \\
\hline & Hip height & .966 & .041 & .097 & & \\
\hline & Waist height & .960 & .149 & .012 & & \\
\hline & Thigh height & .955 & .012 & .122 & & \\
\hline & Crotch height & .952 & -.030 & .117 & & \\
\hline & Knee height & .931 & .035 & .166 & & \\
\hline & Abdominal height & .892 & .146 & .073 & & \\
\hline & Calf height & .806 & .156 & -.029 & & \\
\hline \multirow{16}{*}{ Obesity } & Forearm circ. & .022 & .890 & .025 & \multirow{16}{*}{10.31} & \multirow{16}{*}{30.33} \\
\hline & Elbow circ. & .071 & .882 & .027 & & \\
\hline & Midthigh circ. & .048 & .873 & .144 & & \\
\hline & Knee circ. & .181 & .856 & .118 & & \\
\hline & Thigh circ. & .064 & .837 & .163 & & \\
\hline & Waist circ.(omphalion) & .001 & .819 & .252 & & \\
\hline & Chest circ. & .042 & .817 & .387 & & \\
\hline & Waist circ. & -.046 & .811 & .245 & & \\
\hline & Minimum leg circ. & .129 & .802 & -.024 & & \\
\hline & Calf circ. & .062 & .797 & .102 & & \\
\hline & Neck circ. & .015 & .789 & .153 & & \\
\hline & Abdominal circ. & -.004 & .786 & .254 & & \\
\hline & Upper arm circ. & -.012 & .718 & .219 & & \\
\hline & Hip circ. & .598 & .630 & .056 & & \\
\hline & Foot circ. & .147 & .526 & -.043 & & \\
\hline & Wrist circ. & .037 & .513 & -.140 & & \\
\hline \multirow{5}{*}{ Shoulder } & Posterior shoulder length & .111 & .363 & .703 & 2.59 & 7.61 \\
\hline & Interscye, back & .070 & .418 & .635 & 2.59 & 7.61 \\
\hline & Upperarm length & .490 & -.082 & .616 & 2.59 & 7.61 \\
\hline & Interscye, front & .081 & .407 & .614 & 2.59 & 7.61 \\
\hline & Arm length & .537 & .038 & .557 & 2.59 & 7.61 \\
\hline
\end{tabular}


height factors and obesity factors as independent variables, and size specifications of each body part as dependent variables(Table 7). Although the size system of Brand A is based on stature, chest and waist circumferences, the drop from chest to waist remains at a constant $15 \mathrm{~cm}$. Thus, only stature and chest circumference, without waist circumference, were adopted as independent variables.

The regression equations did not include a constant in order to quantify changing ratios among body parts in accordance with size changes on the basis of the regression equations. The regression results found that $\mathrm{R}^{2}$, which measures the fitness of linear models, was 1.00 against the dependent variables, meaning that $100 \%$ is fit for the sample regression line. Table 6 shows that cervical heights have $\mathrm{R}^{2}=1.00$, fitting $100 \%$ for the sample regression line, and crotch heights have $\mathrm{R}^{2}=0.999$, fitting $99.9 \%$ for the sample regression line.

Against height factors, all regression coefficients indicate posi-

Table 7. Regression equations conducting stature and chest circumference as independent variables

\begin{tabular}{|c|c|c|c|c|c|c|c|}
\hline & \multirow{3}{*}{ Dependent variable } & \multicolumn{4}{|c|}{ Independent variable } & \multirow{3}{*}{$\mathrm{R}^{2}$} & \multirow{3}{*}{$\mathrm{F}$} \\
\hline & & \multicolumn{2}{|c|}{ Stature } & \multicolumn{2}{|c|}{ Chest circ. } & & \\
\hline & & $\mathrm{b}$ & $\beta$ & $\mathrm{b}$ & $\beta$ & & \\
\hline \multirow{12}{*}{ Height } & Cervical height & 0.832 & 0.982 & 0.025 & 0.018 & 1.000 & $7201952.8^{* * *}$ \\
\hline & Axilla height & 0.770 & 1.038 & -0.047 & -0.038 & 1.000 & $2828419.2 * * *$ \\
\hline & Bust height & 0.715 & 1.000 & 0.000 & 0.000 & 1.000 & $2508189.1 * * *$ \\
\hline & Waist height & 0.620 & 1.015 & -0.015 & -0.015 & 1.000 & $1022335.4 * * *$ \\
\hline & Omphalion height & 0.633 & 1.091 & -0.088 & -0.091 & 1.000 & $1331776.4 * * *$ \\
\hline & Abdominal height & 0.556 & 0.983 & 0.016 & 0.017 & 0.999 & $352955.5 * * *$ \\
\hline & Hip height & 0.503 & 1.044 & -0.035 & -0.044 & 0.999 & $740664.4 * * *$ \\
\hline & Gluteal fold height & 0.453 & 1.054 & -0.039 & -0.054 & 0.999 & $745024.8^{* * *}$ \\
\hline & Thigh height & 0.510 & 1.031 & -0.026 & -0.032 & 0.999 & $697138.8 * * *$ \\
\hline & Crotch height & 0.498 & 1.136 & -0.099 & -0.136 & 0.999 & $567060.9 * * *$ \\
\hline & Knee height & 0.252 & 0.977 & 0.010 & 0.023 & 0.999 & $569619.0 * * *$ \\
\hline & Calf height & 0.194 & 1.061 & -0.019 & -0.062 & 0.997 & $148913.2 * * *$ \\
\hline \multirow{16}{*}{ Obesity } & Neck circ. & 0.039 & 0.166 & 0.324 & 0.833 & 0.997 & $145955.3 * * *$ \\
\hline & Bust circ. & -0.080 & -0.140 & 1.082 & 1.140 & 1.000 & $969183.2 * * *$ \\
\hline & Waist circ. & -0.185 & -0.363 & 1.153 & 1.360 & 0.997 & $135089.5^{* * *}$ \\
\hline & Waist circ.(omphalion) & -0.122 & -0.236 & 1.064 & 1.234 & 0.997 & $134525.5^{* * *}$ \\
\hline & Abdominal circ. & -0.059 & -0.111 & 0.973 & 1.109 & 0.997 & $138467.6^{* * *}$ \\
\hline & Hip circumference & 0.171 & 0.301 & 0.659 & 0.699 & 0.999 & $504505.1 * * *$ \\
\hline & Thigh circ. & -0.044 & -0.126 & 0.654 & 1.124 & 0.997 & $130115.8 * * *$ \\
\hline & Midthigh circ. & 0.009 & 0.031 & 0.493 & 0.968 & 0.997 & $165606.3 * * *$ \\
\hline & Knee circ. & 0.104 & 0.467 & 0.197 & 0.533 & 0.998 & $246903.0 * * *$ \\
\hline & Calf circ. & 0.041 & 0.188 & 0.297 & 0.810 & 0.996 & $107045.5^{* * *}$ \\
\hline & Minimum leg circ. & 0.058 & 0.453 & 0.116 & 0.546 & 0.996 & $108918.1 * * *$ \\
\hline & Foot circ. & 0.100 & 0.705 & 0.069 & 0.294 & 0.996 & $114378.1 * * *$ \\
\hline & Upper arm circ. & -0.024 & -0.114 & 0.388 & 1.111 & 0.996 & $96389.3^{* * *}$ \\
\hline & Elbow circ. & 0.041 & 0.260 & 0.192 & 0.739 & 0.997 & $166597.4 * * *$ \\
\hline & Forearm circ. & 0.030 & 0.190 & 0.213 & 0.809 & 0.997 & $158918.7 * * *$ \\
\hline & Wrist circ. & 0.045 & 0.418 & 0.103 & 0.574 & 0.984 & $25551.8^{* * *}$ \\
\hline \multirow{5}{*}{ Shoulder } & Posterior shoulder length & 0.144 & 0.554 & 0.192 & 0.446 & 0.998 & $212954.3 * * *$ \\
\hline & Interscye, front & 0.108 & 0.477 & 0.197 & 0.523 & 0.999 & $296366.1 * * *$ \\
\hline & Interscye, back & 0.103 & 0.425 & 0.231 & 0.575 & 0.998 & $200793.2 * * *$ \\
\hline & Upperarm length & 0.121 & 0.659 & 0.104 & 0.340 & 0.997 & $202277.4 * * *$ \\
\hline & Arm length & 0.207 & 0.639 & 0.194 & 0.361 & 0.998 & $254074.6 * * *$ \\
\hline
\end{tabular}


tive $(+)$ values, telling that taller bodies increase expected height sizes. Against the chest circumference, axilla height, waist circumference, omphalion height, hip height, gluteal fold height, thigh height, crotch height and calf height indicate negative (-) values, demonstrating heavier people tend to have smaller height factors. This result may be attributable to the fact that when a man becomes heavier, his omphalion, hip and calf points are sagging.

All regression coefficients of obesity factors indicate positive $(+)$ values against chest circumferences, showing that heavier bodies increase expected circumference sizes. All regression coefficients of shoulder factors indicate positive $(+)$ values against stature and chest circumference, telling that taller or heavier bodies increase expected shoulder sizes.

According to the regression model above, size specifications can be calculated by using stature and chest circumference. As the regression model was designed on the basis of bigdata, the size specifications secure stronger reliability, not limited to the average samples of each size cell. The size specifications provide guidelines that can be applied to 3D model modification for each size cell. If pattern grading rule is adopted for calculation to cater the taste of target consumers, they will contribute to improving the fitness of ready-made suits.

\subsection{D fitting-model}

The 3D fitting-model is composed of a standard human skeleton structure and a skin surface that is composed of quadrilateral patches. 3D fitting-model is created by the following three steps:

First, create the skeleton and the skin. Then, connect the skeleton and skin so that they move interactively. Finally, apply the weight formula that is developed by the regression analysis so that the skin is moved accordingly. The whole process is conducted in the $3 \mathrm{D}$ Studio Max ${ }^{\mathrm{TM}}$ environment.

Following the process, the 3D fitting-model of standard size is developed, and different sizes of 3D fitting-models are created by size modification (Table 8).

Table 9 presents different body sizes of standard and modified models. The models are saved in the obj format, and measured by Rapidform2006(INUS Technology, Inc Korea). One researcher measured the size five times and calculates the average measurements. As delivered by Table 9, 17 body sizes by regression analysis and 3D model sizes show slight differences of approximately $0.2 \mathrm{~cm}$. The result suggests that the head part accommodates changes in heights, but not detailed sizes of head and face or weight changes. Hence, regardless of chest size, the face and each part are kept in the same shape, resulting 3D modelling different from the

Table 8. Standard and modified sizes of 3D fitting-model

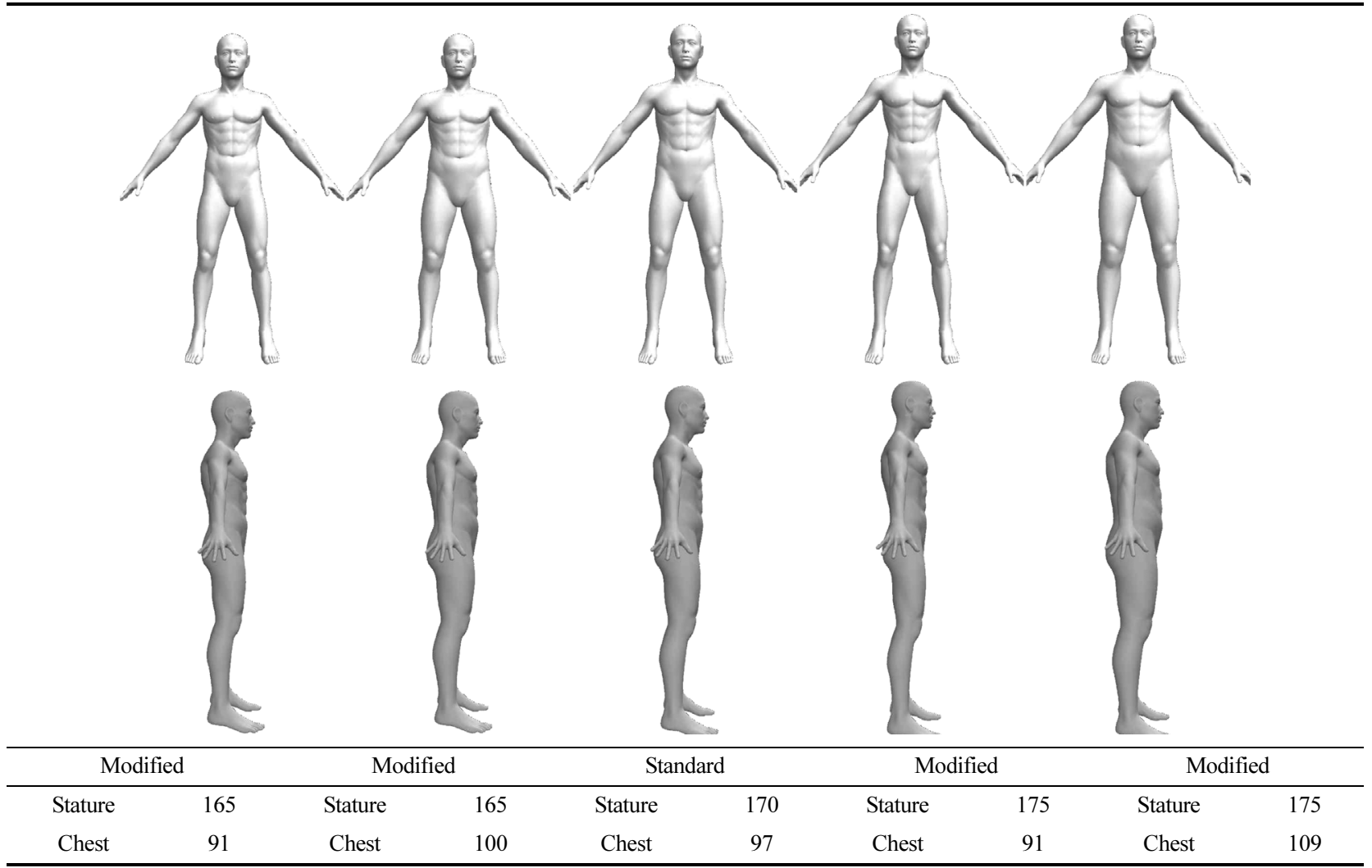


Table 9. Target sizes by regression analysis and $3 \mathrm{D}$ model sizes

(unit ; cm)

\begin{tabular}{|c|c|c|c|c|c|c|c|c|c|c|}
\hline & \multicolumn{2}{|c|}{$165-91$} & \multicolumn{2}{|c|}{$165-100$} & \multicolumn{2}{|c|}{$170-97$} & \multicolumn{2}{|c|}{$175-91$} & \multicolumn{2}{|c|}{ 175-109 } \\
\hline & Regression & $\begin{array}{c}3 \mathrm{D} \\
\text { model }\end{array}$ & Regression & $\begin{array}{c}3 \mathrm{D} \\
\text { model }\end{array}$ & Regression & $\begin{array}{c}3 \mathrm{D} \\
\text { model }\end{array}$ & Regression & $\begin{array}{c}3 \mathrm{D} \\
\text { model }\end{array}$ & Regression & $\begin{array}{c}3 \mathrm{D} \\
\text { model }\end{array}$ \\
\hline Chest circ. & 91.00 & 91.54 & 100.00 & 100.02 & 97.00 & 97.21 & 91.00 & 91.01 & 109.00 & 109.01 \\
\hline Stature & 165.00 & 165.02 & 165.00 & 165.01 & 170.00 & 170.01 & 175.00 & 175.00 & 175.00 & 174.98 \\
\hline Neck circ. & 35.85 & 35.96 & 38.76 & 38.79 & 37.98 & 38.14 & 36.31 & 36.44 & 42.06 & 42.10 \\
\hline Waist circ. & 74.41 & 74.48 & 84.79 & 84.77 & 80.41 & 79.98 & 72.20 & 72.31 & 93.32 & 93.38 \\
\hline Hip circ. & 88.21 & 88.29 & 94.15 & 94.12 & 93.02 & 93.11 & 90.26 & 90.32 & 101.79 & 101.85 \\
\hline Knee circ. & 34.97 & 34.89 & 36.74 & 36.70 & 36.67 & 36.33 & 36.22 & 36.13 & 39.55 & 39.48 \\
\hline Upper arm circ. & 31.33 & 31.15 & 34.82 & 34.77 & 33.53 & 33.36 & 31.04 & 30.98 & 38.07 & 37.99 \\
\hline Forearm circ. & 24.33 & 24.28 & 26.25 & 26.12 & 25.76 & 25.68 & 24.69 & 24.63 & 28.47 & 28.52 \\
\hline Back length & 40.97 & 40.76 & 41.44 & 41.33 & 42.38 & 42.11 & 43.60 & 43.51 & 44.11 & 44.04 \\
\hline Arm length & 53.36 & 53.55 & 53.47 & 53.70 & 55.01 & 55.42 & 57.15 & 57.33 & 56.75 & 56.90 \\
\hline Posterior shoulder length & 41.16 & 41.25 & 42.89 & 43.01 & 43.03 & 43.12 & 42.88 & 42.99 & 46.05 & 46.19 \\
\hline Cervical height & 139.64 & 139.68 & 139.86 & 139.78 & 143.95 & 144.04 & 149.62 & 149.58 & 148.41 & 148.28 \\
\hline Axilla height & 122.88 & 123.01 & 122.46 & 122.58 & 126.45 & 126.89 & 132.12 & 132.01 & 129.74 & 129.65 \\
\hline Waist height & 100.97 & 101.02 & 100.83 & 100.65 & 103.98 & 104.02 & 108.41 & 108.57 & 106.90 & 106.82 \\
\hline Hip height & 79.74 & 79.65 & 79.43 & 79.21 & 82.05 & 82.32 & 85.78 & 85.81 & 84.14 & 84.21 \\
\hline Crotch height & 73.06 & 73.14 & 72.16 & 72.24 & 74.95 & 75.02 & 79.03 & 78.87 & 76.25 & 76.08 \\
\hline Knee height & 42.53 & 42.58 & 42.62 & 42.71 & 43.85 & 43.67 & 45.56 & 45.80 & 45.23 & 45.36 \\
\hline
\end{tabular}

actual sizes. When the head shape changes according to sizes, detailed parts including eyes, hair and ears should be changed accordingly. To this end, an algorithm that connects each part of the fact to skeleton and skin should be added. However, this research that focuses on body parts does not consider such detailed part sizes.

\section{Conclusion}

This study selected a man's fashion brand and developed size specification based on the customers' sizes in order to provide basic data for creating $3 \mathrm{D}$ models with high fitness. To this end, customers who purchased the brand's item(s) in 2011 were examined, and a group of men aged 32 65 among them that delivered frequencies no lower than $1 \%$, were analyzed. Production size improvement was proposed on the basis of crosstabulation analysis on the body measurements, and regression coefficients of each body size were calculated by regression analysis.

This study developed regression equations on body size specifications, which in turn proposed a regression model to proportionately change size specifications of 3D fitting-models in accordance with representative sizes, i.e. stature and chest circumference. The regression model will enable better accommodating actual body shapes when changing sizes of $3 \mathrm{D}$-fitting models.

Based on the each body size calculated by the regression model, a standard model is created, and the skeleton-skin algorithm is applied to the regression model to obtain the results of size changes. Then, the 3D model sizes are tested for size changes as well as measured, which verifies that the regression model reflects body size changes. This result suggests that body analysis of target customers is an appropriate approach to develop and modify 3D model to be used in actual fashion brands.

The fashion industry at home and abroad has tried to adopt the virtual garment technology to reduce the time and resources spent on sample creation. The methodology developed by this study will serve as a case study of body size analysis to help fashion brands develop suitable sizes for their target markets and develop 3D virtual models. This methodology can be applied to diverse brands and different market situations, and will utilized to develop an accurate size system and 3D models that are needed by garment manufacturers. This study also expects follow-up studies on virtual model development based hereon.

\section{Acknowledgements}

This research was supported by the Daegu University Research Grant, 2013. 


\section{References}

Allen, B., Curless, B., \& Popovic, Z. (2003). The space of human body shapes: reconstruction and parameterization from range scans. ACM Transactions on Graphics, 22(3), 587-94. doi:10.1145/ 1201775.882311

Baek, S. Y., \& Lee, K. W. (2012). Parametric human body shape modeling framework for human-centered product design. ComputerAided Design, 44(1), 56-67. doi:10.1016/j.cad.2010.12.006

Charlie, C. L. W. (2005). Parameterization and parametric design of mannequins. Computer-Aided Design, 37(1), 83-98.

Choi, Y. (2012). Sizing system for automatic construction of dress shirt patterns for men. Advanced Materials Research, 605-607, 981988.

CLO virtual Fashion, INC. (2014). Retrieved July 22, 2014, from http:/ /www.clo3d.com/technology/\#MAIN

Gerber Technology, Inc. (2008). Retrieved June 11, 2014, from http:/ /www.gerbertechnology.com/downloads/pdf/html/1view/ index.asp?name $=$ AccuMark_V-Stitcher_Apparel_E

Kim, S. M., \& Park, C. K. (2004). Parametric body model generation for garment drape simulation. Fibers and Polymers, 5(1), 12-18.

Korean Agency for Technology and Standards. (2004). 5th Size Korea Technical Report. Seoul: Government Printing Office.
Li, J., \& Chen, J. (2009). A mannequin modeling method based on section templates and silhouette control. International Journal of Clothing Science and Technology, 21(5), 300-310. doi:10.1108/ 09556220910983795

Optitex. (2008). [On-line]. Retrieved June 11, 2014, from http:// www.optitex.com/en/About_Us/Profile

Seo, H. W., \& Magnenat-Thalmann, N. (2004). An example-based approach to human body manipulation. Graphical Models, 66, 123. doi:10.1016/j.gmod.2003.07.004

Seong, O. J., \& Park, K. A. (2012). A study on the cloth sizing system for middle aged obese men -35-55 years of age-. Journal of the Korean Society of Clothing and Textiles, 36(2), 231-243. doi:10.5850/JKSCT.2012.36.2.231

Yang, H. S., \& Choi, Y. L. (2013). The effect of presentation of apparel products on consumers' approach behavior using $3 \mathrm{~d}$ avatar model. Fashion \& Textile Research Journal, 15(1), 65-72. doi:10.5805/ SFTI.2013.15.1.065

Yoon, J. W., \& Suh, M. A. (2011). Apparel sizing system for obese men in there 20s. The Costume Culture Association, 19(3), 449459 .

(Received 16 February 2015; 1st Revised 22 March 2015; 2nd Revised 2 April 2015; Accepted 10 April 2015)

(C) 2015 (by) the authors. This article is an open access article distributed under the terms and conditions of the Creative Commons Attribution license (http://creativecommons.org/licenses/by/3.0/), which permits unrestricted use, distribution, and reproduction in any medium, provided the original work is properly cited. 